\title{
Residual malaria in Jazan region, southwestern Saudi Arabia: the situation, challenges and climatic drivers of autochthonous malaria
}

Hesham M. Al-Mekhlafi,2,3* (1), Aymen M. Madkhali1,4, Khalid Y. Ghailan ${ }^{5 *}$, Ahmed A. Abdulhaq ${ }^{4}$, Ahmad Hassn Ghzwani ${ }^{1}$, Khalid Ammash Zain ${ }^{1}$, Wahib M. Atroosh ${ }^{2,6}$, Alkhansa Alshabi ${ }^{4}$, Hussein A. Khadashi ${ }^{1}$, Majid A. Darraj ${ }^{7}$ and Zaki M. Eisa ${ }^{8}$

\begin{abstract}
Background: Saudi Arabia and Yemen are the only two countries in the Arabian Peninsula that are yet to achieve malaria elimination. Over the past two decades, the malaria control programme in Saudi Arabia has successfully reduced the annual number of malaria cases, with the lowest incidence rate across the country reported in 2014. This study aims to investigate the distribution of residual malaria in Jazan region and to identify potential climatic drivers of autochthonous malaria cases in the region.

Methods: A cross-sectional study was carried out from 1 April 2018 to 31 January 2019 in Jazan region, southwestern Saudi Arabia, which targeted febrile individuals attending hospitals and primary healthcare centres. Participants' demographic data were collected, including age, gender, nationality, and residence. Moreover, association of climatic variables with the monthly autochthonous malaria cases reported during the period of 2010-2017 was retrospectively analysed.

Results: A total of 1124 febrile subjects were found to be positive for malaria during the study period. Among them, 94.3 and $5.7 \%$ were infected with Plasmodium falciparum and Plasmodium vivax, respectively. In general, subjects aged 18-30 years and those aged over 50 years had the highest (42.7\%) and lowest (5.9\%) percentages of malaria cases. Similarly, the percentage of malaria-positive cases was higher among males than females (86.2 vs 13.8\%), among non-Saudi compared to Saudi subjects (70.6 vs 29.4\%), and among patients residing in rural rather than in urban areas (89.8 vs 10.2\%). A total of 407 autochthonous malaria cases were reported in Jazan region between 2010 and 2017. Results of zero-inflated negative binomial regression analysis showed that monthly average temperature and relative humidity were the significant climatic determinants of autochthonous malaria in the region.
\end{abstract}

\footnotetext{
*Correspondence: halmekhlafi@yahoo.com; khalid.ghailan@gmail.com

${ }^{1}$ Medical Research Centre, Jazan University, Jazan, Kingdom of Saudi Arabia

${ }^{5}$ Faculty of Public Health and Tropical Medicine, Jazan University, Jazan, Kingdom of Saudi Arabia

Full list of author information is available at the end of the article
}

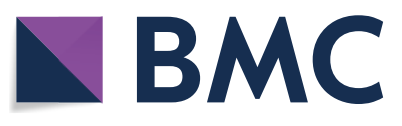

(c) The Author(s) 2021. This article is licensed under a Creative Commons Attribution 4.0 International License, which permits use, sharing, adaptation, distribution and reproduction in any medium or format, as long as you give appropriate credit to the original author(s) and the source, provide a link to the Creative Commons licence, and indicate if changes were made. The images or other third party material in this article are included in the article's Creative Commons licence, unless indicated otherwise in a credit line to the material. If material is not included in the article's Creative Commons licence and your intended use is not permitted by statutory regulation or exceeds the permitted use, you will need to obtain permission directly from the copyright holder. To view a copy of this licence, visit http://creativeco mmons.org/licenses/by/4.0/. The Creative Commons Public Domain Dedication waiver (http://creativecommons.org/publicdomain/ zero/1.0/) applies to the data made available in this article, unless otherwise stated in a credit line to the data. 
Conclusion: Malaria remains a public health problem in most governorates of Jazan region. The identification and monitoring of malaria transmission hotspots and predictors would enable control efforts to be intensified and focused on specific areas and therefore expedite the elimination of residual malaria from the whole region.

Keywords: Malaria, Climatic factors, Elimination, Infectious diseases, Jazan, Saudi Arabia

\section{Background}

Malaria, one of the most common life-threatening infectious diseases, is still a major public health problem worldwide, particularly in tropical and sub-tropical regions. According to the World Health Organization (WHO), about 229 million new cases of malaria were reported worldwide in 2019 and over 3.4 billion people are at risk of infection [1]. Almost $94 \%$ of the malaria cases were reported in the WHO African Region (AFR), while 3.0 and $2.2 \%$ of the cases were recorded in the WHO Southeast Asia Region (SEAR) and Eastern Mediterranean Region (EMR), respectively [1]. Moreover, approximately 409,000 malaria deaths occurred worldwide in 2019, with sub-Saharan Africa accounting for about $95 \%$ of all global malaria deaths $[1,2]$. Plasmodium falciparum is considered the most virulent and prevalent Plasmodium species, accounting for $99.7,69$ and $62.8 \%$ of the reported malaria cases in the AFR, EMR and SEAR regions, respectively [3]. Furthermore, it has been estimated that about 14.3 million malaria cases in 2018 were attributable to Plasmodium vivax and that 3.3 billion people are at risk of vivax malaria infection worldwide [4].

In Saudi Arabia, the national malaria control programme, which was established in 1948, has achieved a tremendous reduction in the annual number of malaria cases, and malaria is now restricted to the southwestern parts of the country, which includes the Aseer and Jazan regions. The number of autochthonous/indigenous (locally transmitted) malaria cases in Saudi Arabia decreased dramatically between 2000 and 2014, from 511 in 2000 to just 30 in 2014, and the country has been included in the E-2020 WHO initiative, which is focused on achieving a target of zero autochthonous cases by 2020 [5]. However, malaria cases increased after 2014, with 5,382 malaria cases reported in 2016, including 272 locally transmitted cases (270 falciparum and two vivax malaria) [6,7]. In the global context, this number of cases is considered high and the country therefore remains determined to make vigorous efforts to achieve E-2020 status.

Progress toward malaria elimination in Saudi Arabia until 2014 has been investigated by several researchers $[8,9]$. However, there is a scarcity of information about the frequency and distribution of malaria cases in Jazan region after 2014. Therefore, this study aims to fill this gap in knowledge and to elucidate the situation regarding the level of residual malaria endemicity in the region, as well as to investigate associations of autochthonous malaria with selected climatic (meteorological) factors over a period of 8 years (2010-2017). In malaria elimination settings, such information is crucial to identify the challenges and further research needs towards the elimination of malaria in the targeted areas.

\section{Methods \\ Study design}

In the first part of this study, a health facility-based survey was carried out between April 2018 and January 2019. Malaria cases were detected through passive case detection among symptomatic febrile patients who visited government hospitals in different governorates of Jazan region. In the second part, association between monthly autochthonous malaria cases and climatic variables was assessed retrospectively for the period 2010 to 2017.

\section{Study area and study population}

The Kingdom of Saudi Arabia lies in the furthermost part of southwestern Asia, bordered by the Red Sea to the west, the Arabian Gulf, United Arab Emirates, and Qatar to the east, Yemen and Oman to the south, and Kuwait, Iraq and Jordan to the north. It is the largest country in the Arab Peninsula, occupying about four-fifths of the Peninsula with a total surface area of approximately $2,000,000 \mathrm{~km}^{2}$ and a total population of about 34 million [10]. Geographically, Saudi Arabia can be divided into two distinct zones: the rain-fed highlands of the western and southwestern regions (Sarawat Mountains) and the vast arid and extra-arid lands of the interior (Najd) [11]. Although Saudi Arabia largely has a desert climate, the climatic conditions differ from one region to another due to the diverse topography of the Kingdom. Generally, the interior parts of the country, which are mostly desert, experience dry hot summers and cold winters, while the coastal areas have high temperature and high humidity and the southwestern part of the country has a moderate climate [12].

Jazan region is located in the southwest corner of the Kingdom of Saudi Arabia between longitude $42.7076^{\circ} \mathrm{E}$ and latitude $17.4751^{\circ} \mathrm{N}$. Jazan region is considered the smallest region in the Kingdom, but it has the highest 
population density in the country, occupying a total land area of approximately $11,671 \mathrm{~km}^{2}$ and having a total population of about 1.8 million. The region consists of three distinct zones: a highland zone (Fayfa Mountains, a part of the Sarawat range) at an elevation of $2500-3000 \mathrm{~m}$ above sea level and with rainfall of more than $200 \mathrm{~mm} /$ year; a hill zone at an elevation of 400-600 m above sea level and with rainfall of less than $200 \mathrm{~mm} /$ year; and, a coastal plain (stretching $300 \mathrm{~km}$ along the southern Red Sea coast and also including more than 100 islands) at an altitude of less than $400 \mathrm{~m}$ above sea level and with little of sporadic rain $[13,14]$. The region contains many valleys (Wadi), such as Wadi Lajab and Wadi Baysh. In addition, there are a few streams in the region as well as 15 dams for the provision of drinking water to cities in the surrounding areas and irrigation water for agricultural activities [15]. Jazan region is divided into 17 governorates, and eight of them were included in this study (Fig. 1).
With regards to the malaria profile of the country, Saudi Arabia can be classified generally into four topographical categories as follows: (1) centre of the country (non-malarious areas); (2) northern and eastern regions (no malaria transmission, but Anopheles superpictus and Anopheles stephensi are still present as possible vectors); (3) western region (sporadic malaria occurrence); and, (4) southern and southwestern regions (low malaria incidence rates) $[7,8]$. The highest number of malaria cases in Saudi Arabia occurred in 1998, when 36,159 cases were reported of which $61 \%$ were detected in Jazan [16]. Jazan region is currently the only region with indigenous malaria cases with few foci for malaria transmission [9, 17]. Anopheles arabiensis is the main vector for malaria in the region; however, other species, which are known to be competent malaria vectors, have also been recorded, including Anopheles sergentii, Anopheles dthali, Anopheles fluviatilis, An. stephensi, An. superpictus, and Anopheles culicifacies [18, 19]. Although mosquitoes can be

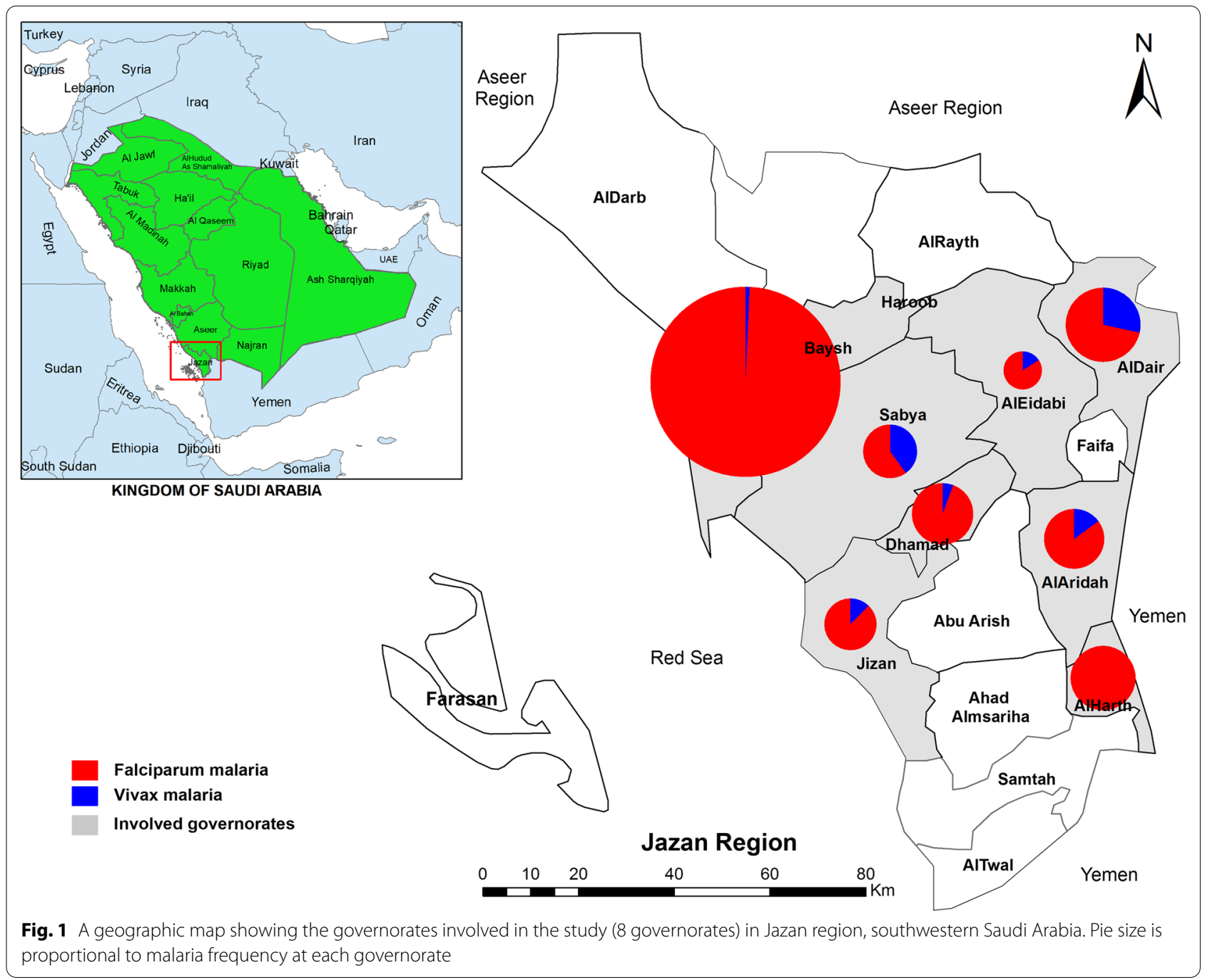


found throughout the year, the presence of Anopheles usually peaks following the rainy season that falls during October to December [20, 21].

Saudi Arabia adopted artemisinin-based combination therapy (ACT) as its anti-malarial drug policy in 2007 [7]. ACT plus primaquine is used for the treatment of uncomplicated falciparum malaria, with artesunate plus sulfadoxine-pyrimethamine (AS + SP) and a combination of artemether-lumefanthrine (AL) as a first-line and second-line treatment, respectively. For severe falciparum malaria, parenteral artesunate and artemether are used as a first-line and second-line treatment, respectively $[7,22]$. According to the policy, parenteral quinine therapy is the preferred option in cases of ACT therapeutic failure or when ACT is not available or contraindicated in the first trimester of pregnancy [7]. On the other hand, vivax malaria is treated with a combination of chloroquine and primaquine for providing radical cure $[7,23]$, whereas chloroquine-resistant vivax malaria is treated with ACT combined with primaquine [7].

From 1 April 2018 to 31 January 2019, blood samples were collected from febrile patients presenting for healthcare at participating healthcare facilities in Jazan region. All patients who were found positive for malaria were invited to take part in the study regardless of their gender, age and nationality. Demographic data about the participants including age, gender, nationality, and residential address (village or town and governorate) were collected by using a standard semi-structured questionnaire or from patients' medical records. The data were extracted from the patients' medical records by trained research assistants on a weekly basis and entered into standard Excel spreadsheets prepared for the study. Laboratory diagnosis data including malaria status, and Plasmodium species and parasite density for malariapositive patients, as well as the date of blood examination were also extracted. Moreover, whole blood samples and Giemsa-stained blood films of all malaria-positive subjects examined during the study period and who gave their consent to participate were collected from the respective healthcare facilities for further examination. In addition, blood samples of randomly selected malarianegative subjects were also collected and re-examined.

\section{Blood sampling and examination}

About $2-3 \mathrm{ml}$ of venous blood was collected from each participant into an EDTA tube clearly labelled with the patient's unique reference number, name, age and gender. Next, a drop of blood was subjected to a rapid diagnostic test (RDT) using the AMP Rapid Test-Malaria p.f./pan kit (AMEDA Labordiagnostik GmbH, Austria). Then, thin and thick blood films were prepared and stained with $3 \%$ of buffer-diluted Giemsa stain for $45 \mathrm{~min}$, and then examined by light microscopy for the presence of malaria parasites. Infection status and parasite density were assessed using the thick films while parasite species and stages were assessed on thin films. A thick blood film was considered negative if no malaria parasites were detected after examining 200 high power fields under a $100 \times$ objective [24].

Parasite density (parasitaemia), expressed as the number of parasites per $\mu \mathrm{l}$ of blood, was determined by counting the asexual stages against 200 white blood cells (WBCs) on the thick blood film, and then multiplying by 40 , based on the WHO-recommended average of 8,000 WBCs per $\mu \mathrm{l}$ of blood in every human being [24]. The level of parasite density (parasitaemia) was graded as low (<100 parasites/ $\mu$ l of blood), moderate (100-9999 parasites/ $\mu \mathrm{l}$ of blood), and severe $(\geq 10,000$ parasites $/ \mu \mathrm{l}$ of blood). Archived malaria positive slides were also collected from respective health centres and re-examined; parasite species and parasitaemia were recorded. For quality control, $25 \%$ of all slides were randomly selected and re-examined by a second reader blinded to the first results. The final results were calculated on the basis of the average of the two readings. Where results were discordant ( $25 \%$ in parasitaemia), a final decision was reached by a third expert microscopist.

\section{Data management and analysis}

Data were double entered by two different research assistants into Microsoft Office Excel 2010 spreadsheets. Then, a third researcher crosschecked the two datasets for accuracy and created a single dataset for analysis. Climatic data for Jazan region, including mean minimum, maximum and average temperature, mean relative humidity, mean wind speed, mean atmospheric pressure, and monthly aggregate rainfall, sandstorm and dust haze events were provided by Sabya governorate's weather station located in central Jazan, and from the annual statistical documents published by the Ministry of Environment, Water, and Agriculture - Saudi Arabia (https:// mewa.gov.sa/ar/Pages/default.aspx) [15, 25], and the General Authority for Statistics (https://www.stats.gov. $\mathrm{sa} / \mathrm{en} / 258$ ) [10].

Data analysis was performed using IBM SPSS Statistics version 27.0-Essentials for R (IBM Corporation, NY, USA). The demographic characteristics of the participants were treated as categorical variables and presented as frequencies and percentages, while the quantitative variables were presented either as mean (standard deviation, SD) or median (interquartile range, IQR). Pearson's Chi-square test was used for $2 \times 1$ contingency table analysis to test the associations between malaria infection and demographic characteristics including age, gender, nationality, and residence [26]. 
For each climatic variable, a monthly average or aggregate was calculated. Malaria cases were grouped by month of onset. In Jazan region, malaria is mostly imported, however, only locally transmitted cases reported between 2010 and 2017 were considered in this study in order to justify potential relationship with local climatic variables. Pearson's correlation coefficients were calculated to determine the correlation between malaria cases and the climatic variables. For biological reasons such as the development and survival of mosquitoes and the development of the parasite within the mosquito, different lags $(0,1,2,3$ and 4$)$ were considered for climatic variables to determine the maximum significant correlations. Since malaria cases was a countable variable with excessive zero counts, and the cases were over-dispersed with a variance greater than the mean, zero-inflated negative binomial regression (ZINB) was applied to identify the relationship between malaria cases and climatic factors at different monthly lags [27].

The covariates were selected based on multicollinearity $(r>0.80)$ and the strength of their statistical correlation with malaria cases (Additional file 1: Table S1). For each variable, the lag that showed the highest significant correlation with malaria cases was included in the ZINB analysis. Moreover, due to the multicollinearity problem detected between minimum temperature and relative humidity, two separate models were generated. Model A included minimum temperature but no relative humidity, and Model B for the converse. Moreover, both models included maximum temperature at lag 1 , average temperature at lag 0 , atmospheric pressure at lag 1 , wind speed at lag 1, number of sandstorms at lag 0 , and number of dust haze events at lag 2 as independent variables. Additional models that included lags with the second highest significant correlation for some variables (e.g. temperature indices, relative humidity and wind speed) were also considered in model fitting. The Akaike's information criterion (AIC) was used to compare goodness-offit between models. All variables that reached a $P$ value of $<0.10$ in the best ZINB models favored by AIC were included in the final reduced model (Model C). To quantify the effects of the included climatic variables, influences or percentage change $\left(e^{\beta}-1\right)$ were computed [28]. A $P$ value of $<0.05$ was considered statistically significant for all statistical tests.

\section{Results}

\section{Frequency and distribution of malaria cases}

A total of 1124 febrile subjects were found to be positive for malaria: 1060 (94.3\%) were infected with P. falciparum and 5.7\% (64/1124) had P. vivax (Fig. 2). With regards to parasitaemia, 27.1, 26.7 and $46.2 \%$ of the patients with falciparum malaria had severe, moderate, and low parasitaemia, respectively. The median (IQR) parasitaemia of falciparum malaria was $1123(456,10,374)$ parasites/ $\mu$ l of blood. The asexual $P$. falciparum parasitaemia from the samples collected ranged from 113 to 33,472 parasites/ $\mu \mathrm{l}$ of blood, with a geometric mean of 5721 parasites $/ \mu \mathrm{l}$. On the other hand, 25.0, 37.5 and $37.5 \%$ of the patients with vivax malaria had severe, moderate and low parasitaemia, respectively. The median (IQR) parasitaemia of vivax malaria was $2084(564,9,076)$ parasites/ $\mu$ l of blood.

Figure 1 shows the distribution of malaria according to residence. Overall, $6.4 \%$ of the confirmed cases were in Baysh followed by Aldair governorate (6.1\%), while only $1.0 \%$ were in Alaridah governorate. Moreover, the majority $(45.3 \%$; $29 / 64)$ of vivax malaria cases were in Aldair followed by Sabya $(18.8 \% ; 12 / 64)$ governorate, while no cases were reported in Alharth governorate. Figure 2 displays the distribution of malaria cases according to nationality. Over half $(54.2 \% ; 609 / 1124)$ of the cases were among Yemeni subjects followed by Saudis (29.4\%),

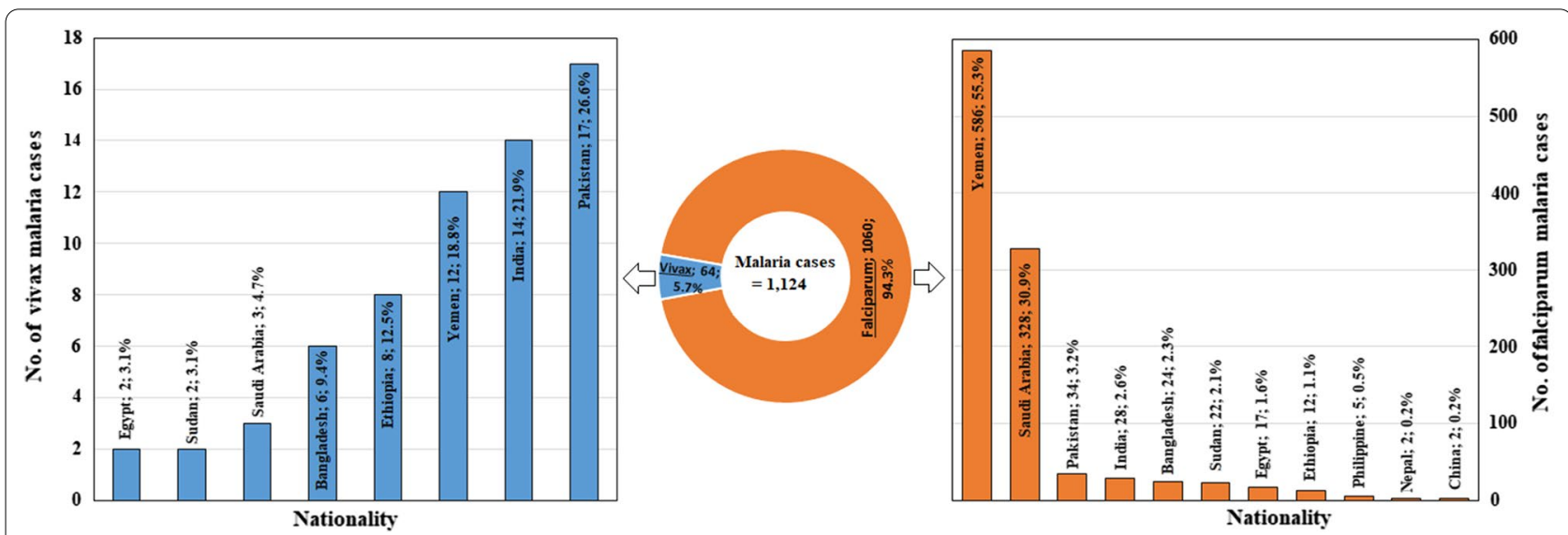

Fig. 2 Distribution of falciparum and vivax malaria cases reported among febrile patients in Jazan region according to patients' nationality 
while the lowest number of cases was found to be among Chinese and Nepalese patients (two cases each). Interestingly, about one quarter $(26.6 \% ; 17 / 64)$ of the vivax malaria cases were among Pakistanis followed by Indians (21.9\%; 14 cases), and Yemenis (18.8\%; 12 cases).

Figure 3 shows that the monthly distribution of malaria cases during the study period. The results showed continuous transmission of malaria throughout the year. Due to an outbreak in Baysh governorate, the percentage of malaria cases increased from 56 in October 2018 to 395 in December 2018. Nonetheless, the monthly malaria cases reported by this study corresponds to the known seasonal transmission of malaria in the region.

Table 1 shows the distribution of malaria cases according to demographic characteristics of the study subjects. The results showed that the percentage of confirmed cases was significantly higher among the males $(86.2 \%)$ compared to females $(13.8 \%)(P<0.001)$. Also, subjects aged $18-30$ years had the highest percentage (42.7\%) of confirmed malaria cases followed by those aged 31-40 years (23.8\%) while those aged over 50 years had the lowest (5.9\%) when compared with other age groups. With regards to nationality, $70.6 \%$ of confirmed malaria cases were non-Saudis and $29.4 \%$ were Saudi subjects and the difference was statistically significant $(P<0.001)$. Similarly, a significantly higher percentage of malaria cases was found among subjects from rural areas (89.8\%) compared to those from urban areas (10.2\%). With regards to species, vivax malaria cases were not found among
Table 1 Distribution of malaria confirmed cases according to demographic factors of febrile patients in Jazan region $(n=1124)$

\begin{tabular}{llcc}
\hline Variables & $\begin{array}{l}\text { Falciparum } \\
\text { malaria } \\
(\mathbf{n}=\mathbf{1 0 6 0})\end{array}$ & $\begin{array}{l}\text { Vivax } \\
\text { malaria } \\
\mathbf{( n = 6 4 )}\end{array}$ & Overall malaria \\
\hline Age groups (years) & & & \\
$<18$ (children) & $146(13.8)$ & $3(4.7)$ & $149(13.3)$ \\
$18-30$ & $458(43.2)$ & $22(34.4)$ & $480(42.7)$ \\
$31-40$ & $247(23.3)$ & $21(32.8)$ & $268(23.8)$ \\
$41-50$ & $145(13.7)$ & $16(25.0)$ & $161(14.3)$ \\
$>50$ & $64(6.0)$ & $2(3.1)$ & $66(5.9)$ \\
Gender & & $4(6.3)$ & $155(13.8)$ \\
Female & $151(14.2)$ & $60(93.8)$ & $969(86.2)$ \\
Male & $909(85.8)$ & & $115(10.2)$ \\
Residence & & $14(21.9)$ & $1009(89.8)$ \\
Urban & $101(9.5)$ & $50(78.1)$ & $331(29.4)$ \\
Rural & $959(90.5)$ & & $793(70.6)$ \\
Nationality & & $3(4.7)$ & \\
Saudis & $328(30.9)$ & $61(95.3)$ & \\
Non-Saudis & $732(69.1)$ & &
\end{tabular}

young children (aged below 10 years) and older persons (aged $\geq 65$ years). Interestingly, four cases $(6.3 \%)$ only of vivax malaria were among female patients, while the rest of the cases (60 cases; 93.7\%) were found among their male counterparts. As regards nationality, three cases (4.7\%) only of vivax malaria were among Saudis, while 61

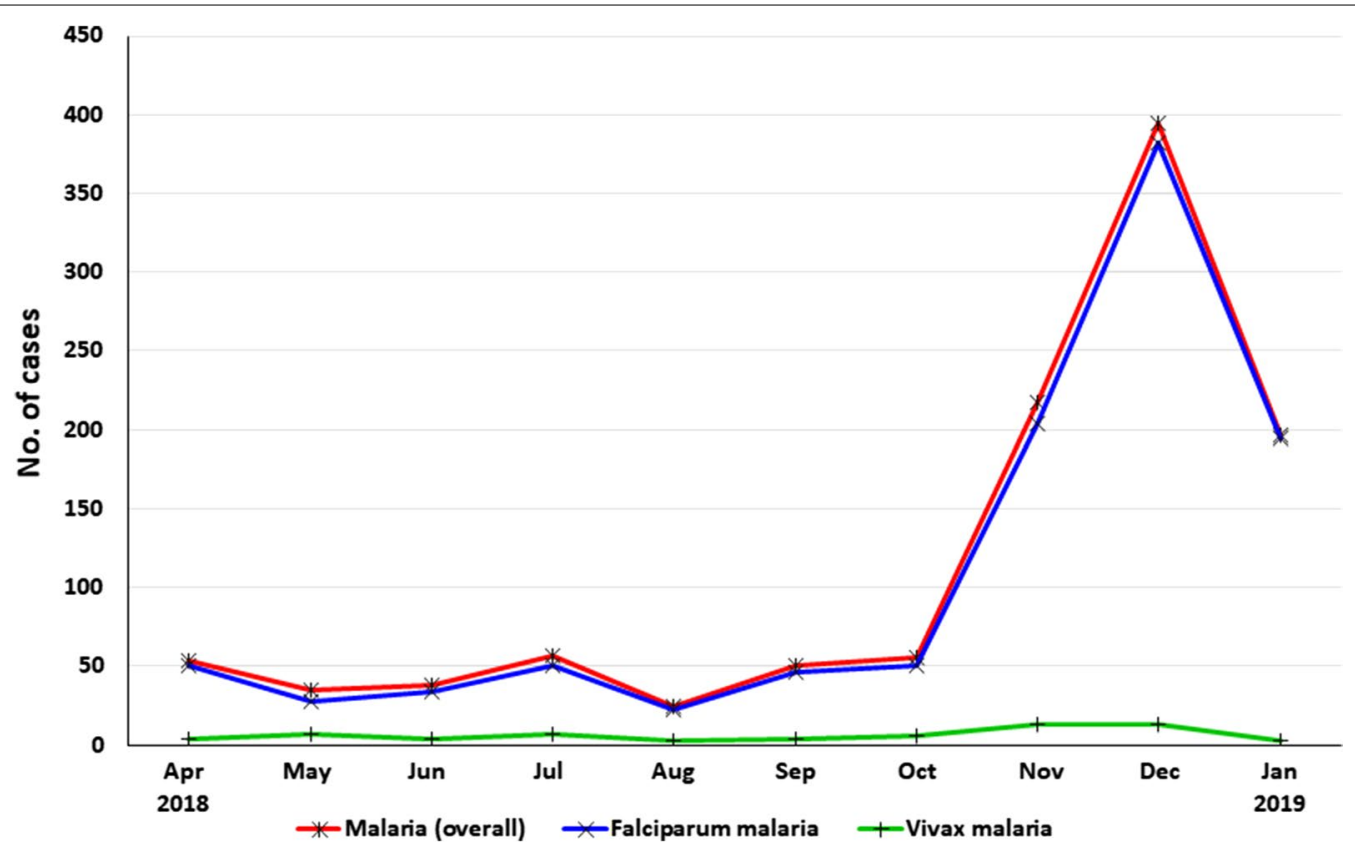

Fig. 3 Monthly distribution of malaria cases among febrile patients in Jazan region during the study period 
Table 2 Mean monthly climatic factors for Jazan region for the period 2010-2017

\begin{tabular}{lcl}
\hline Variables & Mean \pm SD & Range \\
\hline Maximum temperature $\left({ }^{\circ} \mathrm{C}\right)$ & $36.2 \pm 3.1$ & $30.0-42.2$ \\
Minimum temperature $\left({ }^{\circ} \mathrm{C}\right)$ & $25.7 \pm 3.3$ & $17.4-31.8$ \\
Average temperature $\left({ }^{\circ} \mathrm{C}\right)$ & $30.7 \pm 2.8$ & $23.0-35.1$ \\
Relative humidity $(\%)$ & $67.8 \pm 5.5$ & $56.0-82.3$ \\
Rainfall $(\mathrm{mm})$ & $10.8 \pm 16.6$ & $0.0-62.1$ \\
Atmospheric pressure $(\mathrm{hPa})$ & $1006.3 \pm 5.3$ & $974.4-1014.1$ \\
Wind speed $(\mathrm{km} / \mathrm{h})$ & $6.0 \pm 1.0$ & $4.0-9.0$ \\
Number of sandstorms & $1.0 \pm 1.5$ & $0-5$ \\
Number of dust haze events & $16.3 \pm 14.6$ & $0-49$ \\
\hline
\end{tabular}

cases $(95.3 \%)$ were found among non-Saudis. More than three-quarters $(78.1 \%$; $50 / 64)$ of the vivax malaria cases were among rural subjects compared to $21.9 \%$ among their urban counterparts.

\section{Correlation of autochthonous malaria with climate parameters}

Overall, a total of 8,718 malaria cases were reported in Jazan region between 2010 and 2017. Of these, 95.3\% were imported cases and $4.7 \%$ were autochthonous (locally acquired) cases. Table 2 shows the mean monthly climatic factors for Jazan region for the period 20102017. Figure 4A-F and Additional file 1: Table S1 display the correlation between unlagged mean or aggregate

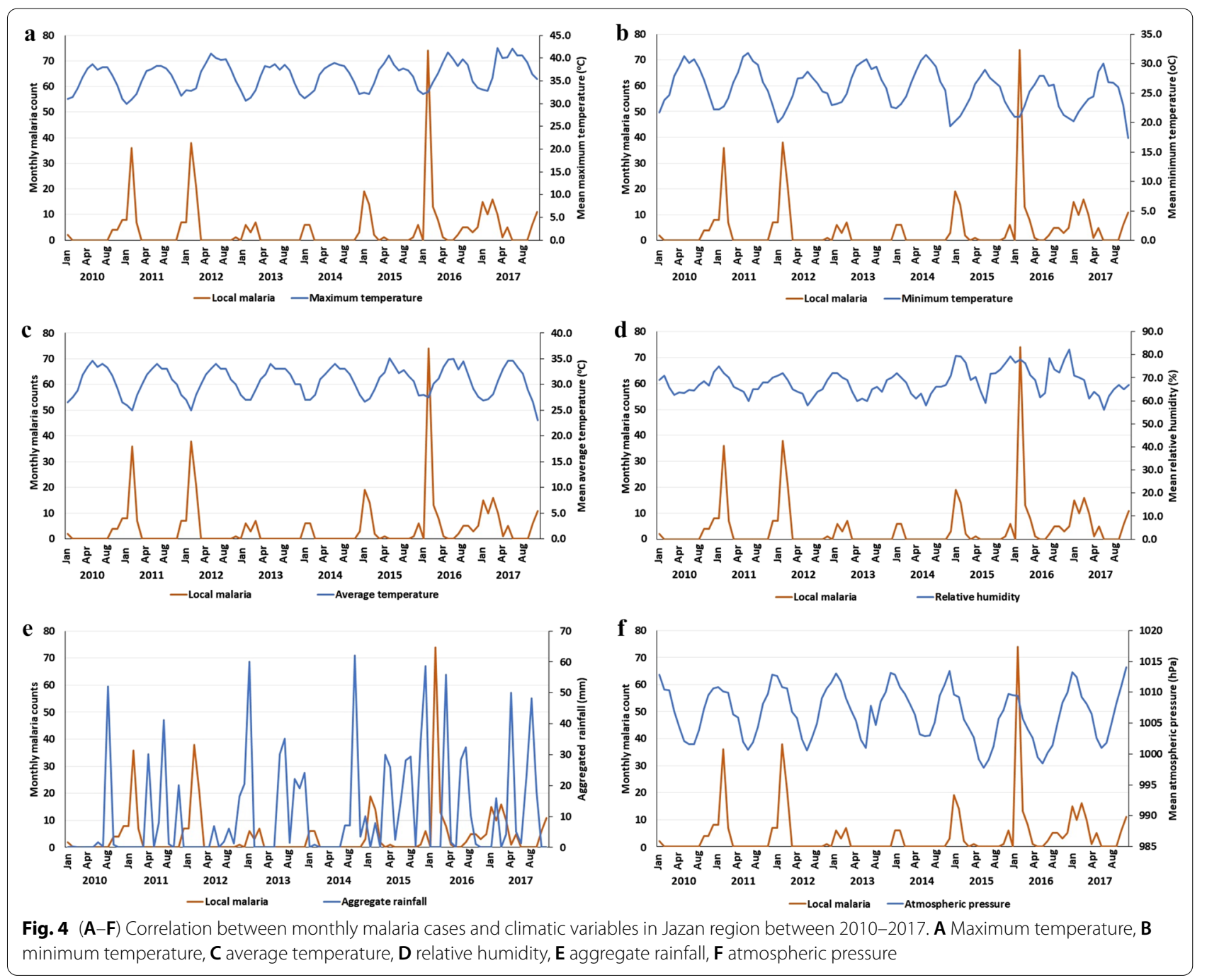


Table 3 Pearson's correlation coefficients of lagged climatic variables and autochthonous malaria cases reported in Jazan region between 2010 and 2017

\begin{tabular}{llllllllll}
\hline & $\begin{array}{l}\text { Maximum } \\
\text { temperature }\end{array}$ & $\begin{array}{l}\text { Minimum } \\
\text { temperature }\end{array}$ & $\begin{array}{l}\text { Average } \\
\text { temperature }\end{array}$ & $\begin{array}{l}\text { Relative } \\
\text { humidity }\end{array}$ & $\begin{array}{l}\text { Aggregate } \\
\text { rainfall }\end{array}$ & $\begin{array}{l}\text { Atmospheric } \\
\text { pressure }\end{array}$ & $\begin{array}{l}\text { Wind } \\
\text { speed }\end{array}$ & $\begin{array}{l}\text { No. of } \\
\text { sandstorm } \\
\text { events }\end{array}$ & $\begin{array}{l}\text { No. of dust } \\
\text { haze events }\end{array}$ \\
\hline Unlagged & $-0.387^{* *}$ & $-0.477^{* *}$ & $-0.492^{* *}$ & $0.420^{* *}$ & -0.157 & $0.281^{* *}$ & -0.171 & $-0.257^{*}$ & -0.070 \\
1-month lag & $-0.403^{* *}$ & $-0.492^{* *}$ & $-0.458^{* *}$ & $0.422^{* *}$ & -0.138 & $0.320^{* *}$ & $-0.318^{* *}$ & $-0.224^{*}$ & $-0.213^{*}$ \\
2-month lag & $-0.331^{* *}$ & $-0.361^{* *}$ & $-0.339^{* *}$ & $0.377^{* *}$ & 0.167 & $0.305^{* *}$ & $-0.227^{*}$ & -0.164 & $-0.297^{* *}$ \\
3-month lag & -0.090 & -0.162 & -0.071 & $0.238^{*}$ & 0.196 & 0.151 & $-0.270^{* *}$ & 0.115 & $-0.256^{*}$ \\
4-month lag & 0.126 & 0.072 & 0.142 & 0.130 & 0.017 & -0.014 & $-0.246^{*}$ & 0.184 & -0.162 \\
\hline
\end{tabular}

** Significant correlation at $P<0.01$

* Significant correlation at $P<0.05$

monthly climatic variables (temperature, rainfall, relative humidity, and atmospheric pressure) and monthly malaria cases over the period 2010 to 2017. The results show that there is a significantly negative correlation of monthly malaria cases with the three temperature indices $(P<0.001)$. On the other hand, the correlation was significantly positive with mean relative humidity $(\mathrm{r}=0.420$; $P<0.001)$ and atmospheric pressure $(\mathrm{r}=-0.281$; $P<0.001)$. Similarly, Table 3 and Fig. $5 \mathrm{~A}-\mathrm{C}$ show a significantly negative correlation of malaria cases with number of sandstorm events $(r=-0.237 ; P<0.01)$. On the other hand, the correlation of malaria cases with wind speed $(r=-0.171)$, aggregate rainfall $(r=-0.157)$ and number of dust haze events $(r=-0.070)$ was not significant $(P>0.05)$.

Correlation of malaria cases with lagged climatic variables was assessed (Table 3). The significant correlation between lagged temperature indices and monthly malaria cases occurred at 1- and 2-month lags with a peak at 1 -month lag period. Similarly, the significant correlation of humidity and wind speed with malaria cases continued to 3-month and 4-month lag periods, respectively. Moreover, other variables correlated significantly with malaria cases at specific lag periods (Table 3). However, the correlation between malaria cases and monthly aggregate rainfall was not significant at all lag periods $(P>0.05)$.

The results of ZINB regression showed both the count model coefficients and the inflation model that contained logit coefficients for predicting excess zeroes (Table 4). In Model A, the negative binomial results showed that mean minimum temperature at 1-month lag and unlagged average temperature had a significant effect on the number of autochthonous malaria cases in Jazan region. In another model (Model B) that included relative humidity instead of minimum temperature, the results showed that relative humidity was the only significant variable. When other variables (at specific lag periods) that showed significant correlation with monthly malaria cases were included instead of the related lags in a stepwise manner, different results were obtained. With regards to ZINB logit coefficients, monthly mean maximum and minimum temperature, both at 1-month lag, and unlagged average temperature were the significant determinants of monthly malaria cases identified by Model A while relative humidity and maximum temperature, both at 1-month lag, and unlagged average temperature were the significant variables in Model B. A reduced model (Model C) showed that average temperature and relative humidity were the significant determinants of malaria cases (Table 4).

Based on AIC, Model C (AIC $=327.260)$ was best suited to predict the monthly autochthonous malaria cases in Jazan region compared to Model A (AIC $=330.893)$ and B $($ AIC $=337.659)$ and other models. Thus, ZINB logit coefficients of Model $C$ were the final results of this regression model (Table 4). The results showed that the odds that monthly autochthonous malaria count would be zero in Jazan region increased (i.e., it is less likely that there will be malaria cases) with an increase of one ${ }^{\circ} \mathrm{C}$ in monthly unlagged average temperature $(\mathrm{OR}=1.88)$. On the other hand, the odds that monthly malaria count would be zero decreased (i.e. it is more likely that there will be malaria cases) with an increase of $1 \%$ in relative humidity $(\mathrm{OR}=0.71)$.

\section{Discussion}

The current study revealed that malaria remains a public health problem in Jazan region, with a total of 1124 confirmed cases were reported among the febrile patients presented at healthcare centres during the study period. Since the introduction of a malaria elimination strategy in 2004, the burden of malaria in Saudi Arabia has been markedly reduced, and the country has successfully decreased the burden and geographic extent of malaria nationwide [29]. However, a limited number of malaria 

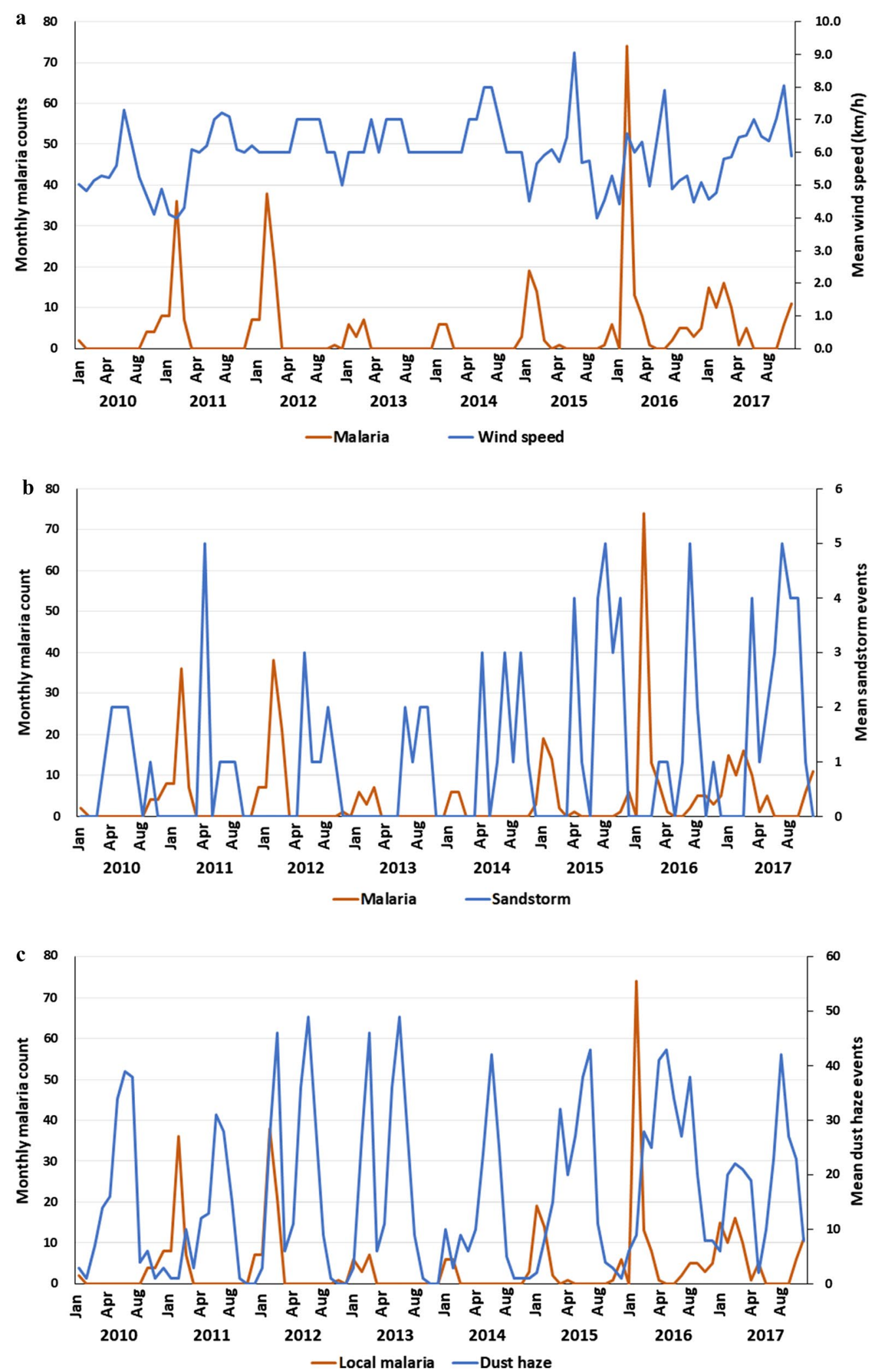

Fig. 5 A-C Correlation between monthly malaria cases and climatic variables in Jazan region between 2010-2017. A Wind speed, B no. of sandstorms, $\mathbf{C}$ no. of dust haze events 
Table 4 Results of zero-inflated negative binomial regression for the relationship between climatic variables and autochthonous malaria reported in Jazan region between 2010 and 2017

\begin{tabular}{|c|c|c|c|c|c|c|c|c|c|c|}
\hline \multirow[t]{2}{*}{ Variables } & \multicolumn{5}{|c|}{ Count model (negative binomial coefficients) } & \multicolumn{5}{|c|}{ Zero-inflated model (logit coefficients) } \\
\hline & $\beta$ & SE & $95 \% \mathrm{Cl}$ & $P$ & $\%$ change $^{\dagger}$ & $\beta$ & SE & $95 \% \mathrm{Cl}$ & $P$ & $\mathrm{OR}^{\ddagger}$ \\
\hline \multicolumn{11}{|l|}{ Model A } \\
\hline Intercept & 16.593 & 3.809 & $9.023,24.163$ & $<0.001^{*}$ & - & -21.481 & 8.775 & $\begin{array}{r}-38.919 \\
-4.043\end{array}$ & 0.014 & - \\
\hline Maximum temperature (lag 1) & -0.095 & 0.099 & $-0.292,0.102$ & 0.336 & -9.06 & -0.736 & 0.351 & $-1.434,-0.038$ & $0.036^{*}$ & 0.48 \\
\hline Minimum temperature (lag 1) & -0.243 & 0.073 & $\begin{array}{l}-0.388 \\
-0.098\end{array}$ & $0.001^{*}$ & -21.57 & 0.704 & 0.258 & $0.191,1.217$ & $0.006^{*}$ & 2.02 \\
\hline Average temperature (lag 0) & -0.157 & 0.078 & $\begin{array}{l}-0.312 \\
-0.002\end{array}$ & $0.045^{*}$ & -14.53 & 0.853 & 0.351 & $0.155,1.551$ & $0.015^{*}$ & 2.35 \\
\hline Atmospheric pressure (lag 1) & -0.131 & 0.182 & $-0.493,0.231$ & 0.130 & -12.28 & 0.196 & 0.638 & $-1.072,1.464$ & 0.758 & 1.22 \\
\hline Wind speed (lag 1) & -0.145 & 0.141 & $-0.425,0.135$ & 0.301 & -11.50 & 0.651 & 0.483 & $-0.309,1.611$ & 0.177 & 1.92 \\
\hline No. of sandstorms (lag 0) & -0.051 & 0.140 & $-0.329,0.227$ & 0.714 & -4.97 & -0.366 & 0.351 & $-1.064,0.332$ & 0.298 & 0.69 \\
\hline No. of dust haze events (lag 2) & 0.001 & 0.127 & $-0.251,0.253$ & 0.999 & 0.10 & 0.308 & 0.322 & $-0.332,0.948$ & 0.339 & 1.36 \\
\hline \multicolumn{11}{|l|}{ Model B } \\
\hline Intercept & 1.683 & 3.260 & $-4.795,8.162$ & 0.817 & - & 35.394 & 13.098 & $9.364,61.424$ & 0.078 & - \\
\hline Maximum temperature (lag 1) & -0.016 & 0.135 & $-0.284,0.252$ & 0.907 & -1.56 & -0.603 & 0.273 & $-1.146,-0.061$ & $0.027^{*}$ & 0.55 \\
\hline Average temperature (lag 0) & -0.152 & 0.087 & $-0.325,0.021$ & 0.079 & -14.10 & 0.796 & 0.346 & $0.108,1.484$ & $0.021^{*}$ & 2.22 \\
\hline Relative humidity (lag 1) & 0.097 & 0.047 & $-0.004,0.190$ & $0.047^{*}$ & 10.19 & -0.393 & 0.145 & $-0.681,-0.105$ & $0.007^{*}$ & 0.68 \\
\hline Atmospheric pressure (lag 1) & 0.246 & 0.474 & $-0.696,1.188$ & 0.603 & 27.94 & -1.830 & 1.349 & $-4.511,0.851$ & 0.175 & 0.16 \\
\hline Wind speed (lag 1) & -0.053 & 0.160 & $-0.371,0.265$ & 0.742 & -5.16 & 0.261 & 0.518 & $-0.768,1.290$ & 0.615 & 1.30 \\
\hline Number of sandstorms (lag 0) & -0.017 & 0.169 & $-0.353,0.319$ & 0.920 & -1.69 & -0.484 & 0.428 & $-1.335,0.367$ & 0.258 & 0.62 \\
\hline $\begin{array}{l}\text { Number of dust haze events } \\
\text { (lag 2) }\end{array}$ & -0.079 & 0.158 & $-0.393,0.235$ & 0.617 & -7.60 & 0.530 & 0.423 & $-0.311,1.371$ & 0.211 & 1.70 \\
\hline \multicolumn{11}{|l|}{ Model C } \\
\hline Intercept & 12.388 & 1.726 & $8.960,15.816$ & $<0.001^{*}$ & - & -14.350 & 4.500 & $\begin{array}{r}-23.293 \\
-5.407\end{array}$ & 0.001 & - \\
\hline Maximum temperature (lag 1) & -0.090 & 0.066 & $-0.221,0.041$ & 0.171 & -8.61 & -0.090 & 0.066 & $-0.221,0.041$ & 0.104 & 0.91 \\
\hline Average temperature (lag 0) & -0.194 & 0.072 & $\begin{array}{l}-0.337 \\
-0.051\end{array}$ & $0.007^{*}$ & -17.63 & 0.631 & 0.212 & $0.210,1.052$ & $0.003^{*}$ & 1.88 \\
\hline Relative humidity (lag 1) & 0.059 & 0.039 & $-0.018,0.136$ & 0.134 & 6.08 & -0.347 & 0.173 & $-0.691,-0.003$ & $0.045^{*}$ & 0.71 \\
\hline
\end{tabular}

$\beta$ : Regression coefficient; SE: Standard error of $\beta ; \mathrm{Cl}$ : Confidence interval for $\beta$

${ }^{\dagger}$ Computed as $\left(\mathrm{e}^{\beta}-1\right)^{*} 100$

₹ Computed as $\left(\mathrm{e}^{\beta}\right)$

* Significant association $(P<0.05)$

foci remain in Jazan and Aseer regions in southwestern Saudi Arabia $[9,30]$.

In the current study, the percentage of febrile subjects found positive for malaria parasites was higher than that reported by previous studies conducted in Jazan and some other regions of the country, including the Makkah region and in the Al-Ahsa governorate in Eastern province [30-33]. El Hassan et al. [9] showed a dual trend of malaria cases in Jazan between 2000 and 2014, i.e., a significant reduction in autochthonous malaria cases (from 35.3 per 10,000 population in 2000 to the lowest rate of 0.11 cases per 10,000 population in 2014) and a constant number of imported malaria cases. A similar situation was also reported in the neighboring Aseer region
[30]. However, since 2015, a steady rise in malaria cases in both Jazan and Aseer regions has been noted [34, 35], and this observation is supported by the findings of the current study. Compared to the very low proportion of autochthonous cases reported annually as compared to imported cases since 2014, the current study found that $4.5 \%(51 / 1124)$ of the cases can be considered autochthonous, with autochthonous cases reported during the outbreak in Baysh governorate were excluded. Hence, generally, it can be said that Saudi Arabia continues to make good progress toward achieving the WHO E-2020 goal [1].

Moreover, the current study revealed that malaria transmission is still active in Jazan region with malaria 
cases identified in 14 governorates (out of 17) during the study period. The findings also showed that malaria in Jazan region occurs throughout the year without any obvious seasonal patterns, a finding that coincides with that reported by a previous study conducted in Aseer region [30]. Likewise, the findings also demonstrated that the monthly number of malaria cases was consistent in all governorates, except Baysh. Indeed, an outbreak of falciparum malaria was reported in Baysh governorate from November 2018 through January 2019, with an approximately two- to three-fold increase in the number of confirmed cases relative to the mean number of cases for the same months in the five preceding years plus two times the standard deviation $[36,37]$. Despite a lack of authoritative information on its spread and determinants, this outbreak could be attributed to a combination of factors, including unusual heavy rainfall and flooding in Jazan region including Wadi Baysh (the largest perennial stream in Saudi Arabia) for 2-3 months before the onset of outbreak, which may have caused an increase in vector breeding sites as well as the arrival of new efficient vectors $[18,21]$. Moreover, the Baysh dam, built in 2009, is one of the largest dams in the country and is situated along the mainstream of Wadi Baysh [38]. Hence, it seems that, unless there are appropriate measures in place, the construction of dams for irrigation and hydroelectric generation could intensify malaria transmission by providing breeding habitats for prominent malaria vector species, especially in areas of unstable or limited transmission $[18,39]$. In addition, increased cross-border importation of malaria [34] and poor awareness of malaria prevention measures among the general population [40], as well as the emerging resistance of the parasites to treatment and the resistance of the vectors to insecticides might also have contributed to this outbreak [19]. Therefore, this malaria outbreak indicates that there is a need for rigorous impact assessments of metrological and climate change-related variables as well as damrelated environmental factors in Jazan region.

The current findings also showed that $P$. falciparum was the predominant cause of malaria in Jazan which is consistent with previous reports $[35,41]$. The majority of vivax malaria cases identified by the current study were among non-Saudi patients, particularly Pakistani patients followed by Indian and Yemeni patients, as compared with only three cases among the Saudi patient group. Although $P$. falciparum is the predominant species in the neighbouring endemic country, Yemen $[42,43]$, the incidence of vivax malaria has been rising since 2015 [4]. In addition, it was recently estimated that over three quarters $(79.5 \%)$ of the global burden of vivax malaria in 2017 was attributable to India, Pakistan and Ethiopia [4].
As regards the distribution of cases according to demographic factors, the current findings showed that malaria was present among all age groups including children below 5 years. However, the percentage of positive for malaria was the highest among patients aged 18-30 years, which corresponds with previous reports $[30,32]$. This finding could be explained by the higher mobility and occupation-related factors among adult individuals, which may lead to higher exposure to mosquito bites. Similarly, the higher percentage of cases reported in the current study among males could be attributed to behavioral differences and the customs and the traditions in the country. For instance, the female population wears clothes that cover the entire body, whereas the male population tends to wear lighter clothing that exposes arms and legs thereby increasing susceptibility to mosquito bites. However, it should be borne in mind that the reported difference could be attributed to the low number of female participants involved in this study. A greater likelihood of infection among the male population has been reported by previous studies undertaken in Jazan region and elsewhere [35, 44, 45]. In contrast, other studies have demonstrated that women are $40 \%$ more likely than men to contract malaria and that pregnant women are at greater risk of malaria infection and also suffer higher morbidity and mortality $[46,47]$.

In addition, the findings showed significantly higher percentage of malaria among non-Saudi patients as compared with Saudi patients, with more than half $(54.2 \%)$ of the cases found among Yemeni patients. These findings are consistent with those previously reported for Jazan [9, 35]. Moreover, among a total of 318 malaria cases reported in Makkah region between 2008 and 2011, nonSaudi patients accounted for $95 \%$, with Pakistanis, Nigerians, and Indians accounting for $62.0 \%$ [32]. Similarly, out of 3151 malaria cases reported in all regions of the country in 2017, 2974 (95\%) were imported cases, while the remaining 177 cases were autochthonous [3].

The porous international borders between countries represent a major challenge to the elimination of malaria, with the Saudi Arabia border with Yemen being a typical example [34, 48]. The migration of malaria-infected humans has been shown to rapidly undermine gains made in malaria control efforts [49]. In Saudi Arabia, imported malaria remains a major problem with a constant flow of imported malaria, mostly among immigrant workers from south Asia (Pakistan, India and Bangladesh), East Africa (Sudan and Ethiopia), and Yemen [30, 50]. In an effort to address this problem, a collaborative Saudi Arabia and Yemen cross-border joint-programme of malaria control was launched in 2002 and remained operational until 2014 before it ceased due to the armed crisis in Yemen. As a result, the incidence of malaria in 
Jazan region dramatically decreased until 2014. However, between 2015 and 2017, it has been estimated that 32\% of all imported infections detected in Saudi Arabia were of Yemeni origin [34]. Coincidentally, the incidence of the locally acquired cases in Saudi Arabia increased $[9,35]$. Moreover, it should be noted that the majority of nonSaudi immigrant workers in the region reside in areas with poor housing and environmental settings that may favor mosquito breeding and malaria transmission. In general, malaria has been traditionally considered as less of a problem in urban areas compared with peri-urban slums/settlements and rural areas [51].

The association between climatic factors and malaria transmission has been extensively studied and the results are quite varied, thereby indicating that this association is complex. Nonetheless, such information from Saudi Arabia and Jazan region is lacking. Although rainfall is considered a critical factor that provides suitable breeding sites for mosquitoes, temperature is a key driver of many vital traits of the development and the life cycle of both the parasite and the mosquito [52-54]. The current study showed that average temperature and relative humidity were the significant climatic determinants of autochthonous malaria in Jazan region. The findings on temperature are consistent with those in previous studies that demonstrated that temperature below $27{ }^{\circ} \mathrm{C}$ was associated with a high incidence rate, while a temperature over $30{ }^{\circ} \mathrm{C}$ was related to the lowest incidence rates $[55,56]$. The optimal temperature for malaria transmission ranges between $16{ }^{\circ} \mathrm{C}$ and $34{ }^{\circ} \mathrm{C}$ and peak transmission occurs at $25^{\circ} \mathrm{C}$ [53], which is $5-7^{\circ} \mathrm{C}$ cooler than that estimated by other previous studies $[57,58]$. Likewise, a positive relationship between malaria and relative humidity has been demonstrated by previous studies elsewhere $[54,55,59]$. High humidity ( $>60 \%$ ) is essential to enhance the lifespan of the mosquito and the development of the parasite in mosquitoes [60].

The current study has some limitations that should be considered when interpreting the above findings. First, data on the distribution of malaria cases between April 2018 and January 2019 came from passive case detection among febrile patients presenting for healthcare at participating health facilities and this limited the ability to detect malaria infection among parasitaemic but asymptomatic individuals. It should be mentioned that according to the Saudi Ministry of Health's statistics, 184,734 individuals were examined for malaria in Jazan region during 2018, and 1516 of them were found positive with a positivity rate of $0.82 \%$ [36]. As a result, the current findings should be interpreted with caution and evaluated as part of the larger context of the malaria situation in the region. Second, as malaria in Jazan is mostly imported, the association between climatic variables and malaria had to rely on small monthly number of autochthonous malaria reported during the period of 2010-2017. Third, the positive cases reported in this study involved only eight out of 17 governorates of Jazan region. Indeed, Farasan Island and Fayfa highlands were reported malariafree [18], while all other governorates share similar epidemiological characteristics. Thus, the findings can be generalized to include those governorates; however, further studies are required to investigate this conjecture.

\section{Conclusions}

This study revealed that Saudi Arabia still has a long way to go to eliminate malaria from the entire country. Despite the continued intensive efforts being made by the Saudi health authorities to combat malaria, numbers of malaria cases are still being reported in most governorates of Jazan region. However, the identification and monitoring of malaria transmission foci would enable control efforts to be intensified and focused on specific areas, and therefore might also ultimately lead to the elimination of residual malaria in the whole region.

Promotion of operational research is crucial to identify and determine the feasibility of innovative and integrated measures that would maximize the effectiveness of control strategies against cross-border malaria as well as to generate and make best use of data to guide malaria elimination efforts. Moreover, further studies on modelling the relationship of malaria and its vectors with metrological and climate change-related factors in Jazan region are essential to predict malaria outbreaks and to understand the transmission dynamics of the disease in southwestern Saudi Arabia.

\section{Supplementary Information}

The online version contains supplementary material available at https://doi. org/10.1186/s12936-021-03846-4.

Additional file 1: Table S1. Pearson's correlation coefficient matrix of unlagged monthly climatic variables and autochthonous malaria cases reported in Jazan region between 2010 and 2017

\section{Acknowledgements \\ The authors would like to thank the administrative and laboratory staff of all hospitals and malaria control programme units involved for their generous cooperation and support. The authors are grateful to all patients for their voluntarily participation in this study.}

\section{Authors' contributions}

HMA KYG and AMM conceived and designed the study. HMA AHG and KAZ conducted the field survey and collection of samples. HMA AHG KAZ and HAK were involved in the laboratory examination of samples. HMA and KYG analysed the data and wrote the paper. ZME provided logistic support for data collection and fieldwork. AMM AAA WMA MAD AA and ZME reviewed and revised the manuscript critically. The manuscript has been approved by all authors prior to submission. All authors read and approved the final manuscript. 


\section{Funding}

The work described here was funded by the Deanship of Scientific Research $8^{\text {th }}$ funding programme, Jazan University (Grant No. JUP8/000250).

\section{Availability of data and materials}

The data that support the findings of this study are available from the corresponding author upon reasonable request.

\section{Declarations}

\section{Ethics approval and consent to participate}

This study was approved by the Research Ethics Committee of Jazan University (Ref. No. REC39/6-250) as well as by the Health Affairs Directorate of King Fahd Central Hospital, Jazan, Saudi Arabia (Registry No. 086), the respective local official authorities. The objectives and procedures of the study were explained to the patients presented at the health facilities. Then, written and signed informed consents were obtained from all adult participants and parents/guardians on behalf of their children. On the other hand, data collected from health facilities were derived from routine laboratory investigations data of the respective health facilities. Patient names have been anonymized and informed consents were not obtained. All malaria-positive individuals were treated at the respective healthcare facility with the standard medication according to the national malaria drug policy.

\section{Consent for publication}

Not applicable.

\section{Competing interests}

The authors declare that they have no competing interests.

\section{Author details}

${ }^{1}$ Medical Research Centre, Jazan University, Jazan, Kingdom of Saudi Arabia. ${ }^{2}$ Department of Parasitology, Faculty of Medicine, University of Malaya, 50603 Kuala Lumpur, Malaysia. ${ }^{3}$ Department of Parasitology, Faculty of Medicine and Health Sciences, Sana'a University, Sana'a, Yemen. ${ }^{4}$ Department of Medical Laboratory Technology, Faculty of Applied Medical Sciences, Jazan University, Jazan, Kingdom of Saudi Arabia. ${ }^{5}$ Faculty of Public Health and Tropical Medicine, Jazan University, Jazan, Kingdom of Saudi Arabia. ${ }^{6}$ Department of Microbiology and Parasitology, Faculty of Medicine and Health Sciences, University of Aden, Aden, Yemen. ${ }^{7}$ Department of Internal Medicine, Faculty of Medicine, Jazan University, Jazan, Kingdom of Saudi Arabia. ${ }^{8}$ Saudi Centre for Disease Prevention and Control, Ministry of Health, Jazan, Kingdom of Saudi Arabia.

Received: 6 January 2021 Accepted: 6 July 2021

Published online: 13 July 2021

\section{References}

1. WHO. World malaria report 2020. Geneva: World Health Organization; 2020. https://www.who.int/publications/i/item/9789240015791. Accessed 15 Dec 2020.

2. GBD 2019 Diseases and Injuries Collaborators. Global burden of 369 diseases and injuries in 204 countries and territories, 1990-2019: a systematic analysis for the Global Burden of Disease Study 2019. Lancet. 2020;396:1204-22.

3. WHO. World Malaria Report 2017. Geneva: World Health Organization, 2018. Available at: https://www.who.int/malaria/publications/worldmalaria-report-2017/en/. Accessed 17 Aug 2020.

4. Battle KE, Lucas TCD, Nguyen M, Howes RE, Nandi AK, Twohig KA, et al. Mapping the global endemicity and clinical burden of Plasmodium vivax, 2000-17: a spatial and temporal modelling study. Lancet. 2019;394:332-43.

5. WHO. Global technical strategy for malaria 2016-2030. Geneva: World Health Organization, 2015. Available at: https://www.who.int/malaria/ publications/atoz/9789241564991/en/. Accessed 26 Sep 2020.

6. Soliman RH, Garcia-Aranda P, Elzagawy SM, Hussein BE, Mayah WW, Martin Ramirez A, et al. Imported and autochthonous malaria in West Saudi Arabia: results from a reference hospital. Malar J. 2018;17:286.
7. Ministry of Health. National Malaria Drug Policy. Riyadh: Ministry of Health, 2018. https://www.moh.gov.sa/Ministry/About/Health\%20Pol icies/029.pdf. Accessed 10 Nov 2020.

8. Coleman M, Al-Zahrani MH, Coleman M, Hemingway J, Omar A, Stanton $\mathrm{MC}$, et al. A country on the verge of malaria elimination-the Kingdom of Saudi Arabia. PLoS One. 2014;9:e105980.

9. El Hassan IM, Sahly A, Alzahrani MH, Alhakeem RF, Alhelal M, Alhogail A, et al. Progress toward malaria elimination in Jazan Province, Kingdom of Saudi Arabia: 2000-2014. Malar J. 2015;14:444.

10. General Authority for Statistics (GASTAT), Kingdom of Saudi Arabia. Census 2010. Available at: https://www.stats.gov.sa/en/13. Accessed 25 Nov 2020.

11. Patlakas P, Stathopoulos C, Flocas H, Kalogeri C, Kallos G. Regional climatic features of the Arabian Peninsula. Atmosphere. 2019;10:220.

12. Almazroui $M$, Islam MN, Jones PD, Athar H, Rahman MA. Recent climate change in the Arabian Peninsula: seasonal rainfall and temperature climatology of Saudi Arabia for 1979-2009. Atmos Res. 2012;111:29-45.

13. Subyani AM. Geostatistical study of annual and seasonal mean rainfall patterns in southwest Saudi Arabia. Hydrol Sci J. 2004;49:803-17.

14. Lashin A, Al AN. The geothermal potential of Jizan area, southwestern parts of Saudi Arabia. Int J Phys Sci. 2012;7:664-75.

15. MEWA. Annual Statistical Book 2019. Riyadh: Ministry of Environment, Water, and Agriculture, 2019. https://mewa.gov.sa/ar/Pages/default.aspx. Accessed 30 Nov 2020.

16. WHO. World Malaria Report 2005. Geneva: World Health Organization, 2005. https://www.who.int/malaria/publications/atoz/9241593199/en/. Accessed 01 Dec 2020.

17. Abdoon AM, Alshahrani AM. Prevalence and distribution of anopheline mosquitoes in malaria endemic areas of Asir region, Saudi Arabia. East Mediterr Health J. 2003;9:240-7.

18. Alzahrani MH, McCall $\mathrm{P}$, Hassan A, Omar Al, Abdoon AM. Impact of irrigation system on malaria transmission in Jazan Region Saudi Arabia. Open J Trop Med. 2017;1:7-15.

19. Madkhali AM, Al-Mekhlafi HM, Atroosh WM, Ghzwani AH, Zain KA Abdulhaq AA, et al. Increased prevalence of pfdhfr and pfdhps mutations associated with sulfadoxine-pyrimethamine resistance in Plasmodium falciparum isolates from Jazan Region, Southwestern Saudi Arabia: important implications for malaria treatment policy. Malar J. 2020;19:446.

20. Alahmed AM, Al Kuriji MA, Kheir SM, Al Haqawi HM, Sultan EAA. Mosquito (Diptera: Culicidae) and their seasonal activity in Jazan Region, Saudi Arabia. J Saudi Soc Agric Sci. 2010;9:136-8.

21. Waheed $\mathrm{SM}$, Bashir $\mathrm{NHH}$, Alzahrani $\mathrm{MH}$, Abd Elrahman $\mathrm{SH}$, Alsheikh AA, Dafalla OM, et al. Vectorial role of An dthali (Diptera: Culicidae) as a malaria vector in Jazan region/Kingdom of Saudi Arabia. Int J Mosquito Res. 2018;5:49-55.

22. Nzila A, Al-Zahrani I. Drugs for the treatment of malaria in the Kingdom of Saudi Arabia. Saudi Med J. 2013:34:569-78.

23. WHO. Guidelines for the treatment of malaria. Geneva: World Health Organization, 2015. https://www.who.int/publications/i/item/97892 41549127. Accessed 13 Mar 2021.

24. WHO. Microscopy for the detection, identification and quantification of malaria parasites on stained thick and thin blood films in research settings. Geneva: World Health Organization, 2015. https://apps.who.int/iris/ handle/10665/163782. Accessed 30 Jan 2021.

25. MEWA. Annual Statistical Book 2018. Riyadh: Ministry of Environment, Water, and Agriculture, 2018. Available at: https://mewa.gov.sa/ar/Pages/ default.aspx. Accessed 30 Nov 2020.

26. Richardson JT. The analysis of $2 \times 1$ and $2 \times 2$ contingency tables: an historical review. Stat Methods Med Res. 1994;3:107-33.

27. Lee JH, Han G, Fulp WJ, Giuliano AR. Analysis of overdispersed count data: application to the Human Papillomavirus Infection in Men (HIM) Study. Epidemiol Infect. 2012;140:1087-94.

28. Li T, Yang Z, Wang M. Temperature, relative humidity and sunshine may be the effective predictors for occurrence of malaria in Guangzhou, southern China, 2006-2012. Parasit Vectors. 2013;6:155.

29. Alzahrani MH, Kondrashin A, Snow B. Progress toward malaria elimination in the Kingdom of Saudi Arabia 2004-2015: a success story. Riyadh, 2019. https://www.moh.gov.sa/Ministry/MediaCenter/Publications/Docum ents/Malaria.pdf. Accessed 15 Feb 2021. 
30. Alshahrani AM, Abdelgader TM, Saeed I, Al-Akhshami A, Al-Ghamdi M, Al-Zahrani $\mathrm{MH}$, et al. The changing malaria landscape in Aseer region, Kingdom of Saudi Arabia: 2000-2015. Malar J. 2016;15:538.

31. Memish ZA, Alzahrani M, Alhakeem RF, Bamgboye EA, Smadi HN. Toward malaria eradication in Saudi Arabia: evidence from 4-year surveillance in Makkah. Ann Saudi Med. 2014;34:153-8.

32. Al-Mohammed HI, Ferchichi MS. Epidemiological trends over a ten-year period of malaria in a non-endemic area of Saudi Arabia. Int J Curr Microbiol App Sci. 2016;5:1-8.

33. Abosalif KOA, Ejaz H, Almadini A, Alghamdi S, Alhaily M, Albalawi F, et al. Recent trend in the prevalence of Plasmodium falciparum in Jazan area, Kingdom of Saudi Arabia. Pak J Med Health Sci. 2018;13:173-5.

34. Al Zahrani MH, Omar Al, Abdoon AMO, Ibrahim AA, Alhogail A, Elmubarak $M$, et al. Cross-border movement, economic development and malaria elimination in the Kingdom of Saudi Arabia. BMC Med. 2018;16:98.

35. Hawash $\mathrm{Y}$, Ismail $\mathrm{K}$, Alsharif $\mathrm{K}$, Alsanie W. Malaria prevalence in a low transmission area, Jazan district of southwestern Saudi Arabia. Korean J Parasitol. 2019;57:233-42.

36. Ministry of Health. Statistical yearbook 2018. Riyadh: Ministry of Health, 2019. https://www.moh.gov.sa/en/Ministry/Statistics/book/Documents/ book-Statistics.pdf. Accessed 15 Apr 2021.

37. WHO. Field guide for malaria epidemic assessment and reporting. Geneva: World Health Organization; 2004. https://www.who.int/malar ia/publications/atoz/who_htm_mal_2004_1097/en/. Accessed 13 Mar 2021.

38. Abu-Abdullah MM, Youssef AM, Maerz NH, Abu-AlFadail E, Al-Harbi HM, Al-Saadi NS. A flood risk management program of Wadi Baysh dam on the downstream area: an integration of hydrologic and hydraulic models, Jizan Region, KSA. Sustain. 2020;12:1069.

39. Kibret S, Glenn Wilson G, Ryder D, Tekie H, Petros B. Environmental and meteorological factors linked to malaria transmission around large dams at three ecological settings in Ethiopia. Malar J. 2019;18:54.

40. Khairy S, Al-Surimi K, Ali A, Shubily HM, Al Walaan N, Househ M, et al. Knowledge, attitude and practice about malaria in south-western Saudi Arabia: a household-based cross-sectional survey. J Infect Public Health. 2017;10:499-506.

41. Dafalla OM, Alsheikh AA, Abakar AD, Mohammed WS, Nour BYM, Shrwani KJ, Noureldin EM. Identification of Plasmodium species from outdated blood samples by nested-PCR compared with microscopy diagnosis in Jazan region, Saudi Arabia. Biosc Biotech Res Comm. 2017;10(68):75.

42. Atroosh WM, Al-Mekhlafi HM, Al-Jasari A, Sady H, Al-Delaimy AK, Nasr NA, et al. Genetic variation of pfhrp2 in Plasmodium falciparum isolates from Yemen and the performance of HRP2-based malaria rapid diagnostic test. Parasit Vectors. 2015;8:388.

43. Alwajeeh TS, Abdul-Ghani R, Allam AF, Farag HF, Khalil SSM, Shehab AY, et al. Uncomplicated falciparum malaria among schoolchildren in Bajil district of Hodeidah governorate, west of Yemen: association with anaemia and underweight. Malar J. 2020;19:358.

44. Alshahrani AM, Abdelgader TM, Mohya M, Jubran S, Abdoon A, Daffalla AA, et al. Risk associated with malaria infection in Tihama Qahtan, Aseer region, Kingdom of Saudi Arabia: 2006-2007. Malar Control Elimin. 2019;5:144.

45. Pathak S, Rege M, Gogtay NJ, Aigal U, Sharma SK, Valecha N, et al. Agedependent sex bias in clinical malarial disease in hypoendemic regions. PLOS ONE. 2012;7:e35592.
46. Desai M, ter Kuile FO, Nosten F, McGready R, Asamoa K, Brabin B, et al. Epidemiology and burden of malaria in pregnancy. Lancet Infect Dis. 2007:7:93-104.

47. Jenkins R, Omollo R, Ongecha M, Sifuna P, Othieno C, Ongeri L, et al. Prevalence of malaria parasites in adults and its determinants in malaria endemic area of Kisumu County. Kenya Malar J. 2015;14:263.

48. Wangdi K, Gatton ML, Kelly GC, Clements AC. Cross-border malaria: a major obstacle for malaria elimination. Adv Parasitol. 2015;89:79-107.

49. Wickramage K, Premaratne RG, Peiris SL, Mosca D. High attack rate for malaria through irregular migration routes to a country on verge of elimination. Malar J. 2013;12:276.

50. Snow RW, Amratia P, Zamani G, Mundia CW, Noor AM, Memish ZA, et al The malaria transition on the Arabian Peninsula: progress toward a malaria-free region between 1960-2010. Adv Parasitol. 2013:82:205-51.

51. Hay SI, Guerra CA, Tatem AJ, Atkinson PM, Snow RW. Urbanization, malaria transmission and disease burden in Africa. Nat Rev Microbiol. 2005;3:81-90.

52. Blanford Jl, Blanford S, Crane RG, Mann ME, Paaijmans KP, Schreiber KV, Thomas MB. Implications of temperature variation for malaria parasite development across Africa. Sci Rep. 2013;3:1300.

53. Mordecai EA, Paaijmans KP, Johnson LR, Balzer C, Ben-Horin T, de Moor E, et al. Optimal temperature for malaria transmission is dramatically lower than previously predicted. Ecol Lett. 2013;16:22-30.

54. Hundessa S, Williams G, Li S, Guo J, Zhang W, Guo Y. The weekly associations between climatic factors and Plasmodium vivax and Plasmodium falciparum malaria in China, 2005-2014. Trans R Soc Trop Med Hyg. 2017:111:211-9.

55. Alemu A, Abebe G, Tsegaye W, Golassa L. Climatic variables and malaria transmission dynamics in Jimma town, South West Ethiopia. Parasit Vectors. 2011;4:30.

56. Yé Y, Louis VR, Simboro S, Sauerborn R. Effect of meteorological factors on clinical malaria risk among children: an assessment using village-based meteorological stations and community-based parasitological survey. BMC Public Health. 2007;7:101.

57. Craig MH, Snow RW, le Sueur D. A climate-based distribution model of malaria transmission in sub-Saharan Africa. Parasitol Today. 1999;15:105-11.

58. Parham PE, Michael E. Modeling the effects of weather and climate change on malaria transmission. Environ Health Perspect. 2010;118:620-6.

59. Mohammadkhani M, Khanjani N, Bakhtiari B, Sheikhzadeh K. The relation between climatic factors and malaria incidence in Kerman, South East of Iran. Parasite Epidemiol Control. 2016;1:205-10.

60. Akinbobola A, Omotosho JB. Predicting malaria occurrence in southwest and north central Nigeria using meteorological parameters. Int J Biometeorol. 2013;57:721-8.

\section{Publisher's Note}

Springer Nature remains neutral with regard to jurisdictional claims in published maps and institutional affiliations.

Ready to submit your research? Choose BMC and benefit from

- fast, convenient online submission

- thorough peer review by experienced researchers in your field

- rapid publication on acceptance

- support for research data, including large and complex data types

- gold Open Access which fosters wider collaboration and increased citations

- maximum visibility for your research: over $100 \mathrm{M}$ website views per year

At $\mathrm{BMC}$, research is always in progress.

Learn more biomedcentral.com/submissions 